\title{
MODELLING OF PROCESS FORCES FOR COMPLEX MULTIAXIAL TURNING PROCESSES
}

\author{
B. Denkena ${ }^{1}$, A. Kroedel ${ }^{1}$, L. Ellersiek ${ }^{1}$, F. Zender ${ }^{1 *}$ \\ ${ }^{1}$ Leibniz Universitaet Hannover, Institut für Fertigungstechnik und Werkzeugmaschinen, 30823 Garbsen, Germany \\ *Corresponding author; e-mail: zender@ifw.uni-hannover.de
}

\begin{abstract}
Increasing demands regarding productivity and component quality are a major challenge in turning. To meet these demands, complex multiaxial turning processes like enhanced variants of the trochoidal turning processes are increasingly used. For these processes, the tool path is optimized to achieve advantageous cutting conditions and thus higher productivity. However, the process forces and their relations to the process parameters for these processes are currently unknown, which complicates the process design and calculation of required clamping forces.

This paper presents a simulation based approach to estimate the process forces of complex multiaxial turning processes. Therefore, a dexel based material removal simulation is used to calculate the chip parameters, e.g. undeformed chip thickness, and the chip cross-sectional area. On this basis, the process forces are modelled as a function of the undeformed chip thickness and undeformed chip width. By this, the force model is parameterized and the calculated process forces are validated by comparison with process force measurements.
\end{abstract}

\section{Keywords:}

process forces; turning; dexel model; material removal simulation

\section{INTRODUCTION}

The accurate prediction of the occurring process forces in turning is crucial for the right dimensioning of the workpiece clamping, the machine drives or the optimization of the cutting parameters. For conventional turning processes, various process force models exist. Most of these process force models are based on the chip cross sectional area and proportionality force coefficient, usually referred to as specific process force [Arrazola 2013].

An example of a model, which is widely used in the industry to estimate the process forces of turning processes, is the process force model of Victor and Kienzle in [Victor 1952]:

$$
F_{c}=k_{c 1,1} \cdot b \cdot h^{1-c}
$$

The cutting force $F_{c}$ is modelled as proportional to the undeformed chip width $b$ and the thickness of the undeformed chip thickness $h$ with an exponential slope value 1-c. The slope value is used to take into account that the specific cutting force decreases with rising $h$ [Victor 1952]. For the other components of the process force, this model can be used accordingly. While the Victor-Kienzle model can be used with conventional turning processes, it is not suitable for processes with $\mathrm{h}$ less than $0.1 \mathrm{~mm}$ and a ratio of $b$ to $h$ of less than 4 , because large deviations compared to the measured forces occur. Additionally, it has to be noted that the model is inaccurate when the corner radius of the tool is large compared to the cutting depth or a round tool is used [Koehler 2010].

In [Altintas 2012] two different approaches to calibrate the force coefficients of a process force model are described, namely the mechanistic approach and the use of an oblique cutting force model. The oblique cutting force model starts from the measured forces of the orthogonal cut, which then are adapted regarding e.g. the shear behaviour and tool geometry for the considered process. For the mechanistic approach, several cutting experiments with varying cutting parameters and a specific cutting tool are made, from which the force coefficients are inversely calculated. The oblique model has the advantage that the force coefficients can be calculated for arbitrary tool geometries. Compared to this, the mechanistic cutting model has the advantage of being usually more accurate and easier to implement since the models are parameterized with the specific cutting tool geometry [Altintas 2012].

An approach to expand the model of Kienzle is presented in [Köhler 2010]. The extension aims to apply the process forces model of Kienzle for smaller $h$ and smaller ratios of $b$ to $h$ and to take the effect of the corner radius into account. The model is based on the effective width of the undeformed chip $b^{*}$ and the effective undeformed chip thickness $h^{*}$, which are displayed in Fig. 1 [Köhler 2010]. With those parameters, a more precise definition of the shape of 
the undeformed chip is possible. This results in the following function to calculate the cutting force:

$F_{c}=k_{c 1,1} \cdot b^{*} \cdot\left(h^{*}\right)^{m_{c}^{*}}$

Here, $m_{c}^{*}$ is used as the material specific slope value. Since material and process specific correction factors are used, the transferability to other applications is limited. Furthermore, round inserts with their very large ratio of tool radius to cutting depth were not investigated.

\section{conventional chip thickness $h$}

effective chip thickness $h^{*}$
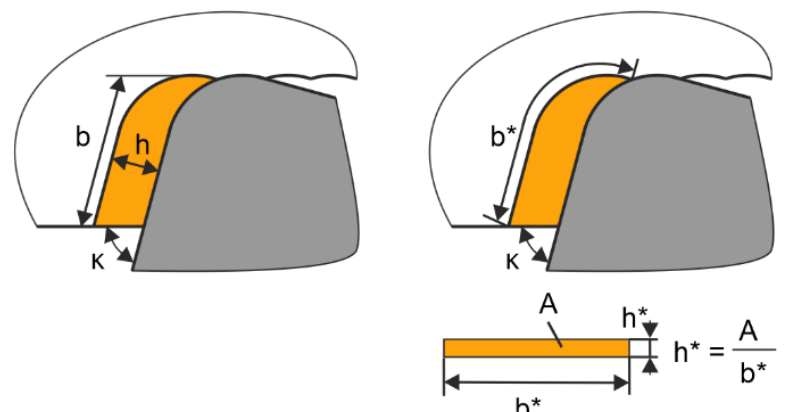

[Köhler 2010]

Ze/107491 @IFW

Fig. 1: Concept of effective undeformed chip thickness

[Zaeh 2009] displays a combined model of the process forces and the behaviour of the machine tool. The process force model is based on an oblique cutting force model, which uses a FEM simulation of the material flow to estimate the flow stress and the process forces. Additionally, nonlinear friction conditions are taken into account [Zaeh 2009].

In [Lorong 2011] the chatter behaviour of turning of thin walled workpieces is investigated. The model introduced there consists of two parts, a FEM-model to calculate the dynamic behaviour of the workpiece and a material removal simulation, to calculate the acting process forces. A dexe model with radial dexels is used to simulate a cylindrical turning process. The process forces are calculated based on the process force model of Kienzle [Lorong 2011].

[Dorlin 2016] presents a cutting force model for turning operations on Ti6Al4V titanium alloy, where especially the influence of the distance between the clearance face and the centre of the workpiece, here called the clearance face contact radius, is investigated. Based on experiments the influences of various factors on the process forces are investigated. Here cylindrical turning, face turning and boring processes are investigated. From these experiments, a mechanistic cutting force model based on the undeformed chip geometry, which takes the clearance face contact radius into account, is derived [Dorlin 2016].

In [Weng 2017], an analytical process force model for round inserts is introduced. The process force model is derived from an oblique force model. Due to this, a detailed geometrical analysis of the undeformed chip cross-section is made. Additionally, the shear and friction behaviour and the chip flow direction are investigated for the used round cutting insert [Weng 2017].

In this paper, process forces of an enhanced trochoidal turning process are analysed in detail. For this process, the toolpath of a round cutting insert is optimized to constantly achieve a maximum cutting edge angle $K$ and thus a constant maximum undeformed chip thickness. This is possible, because for round inserts the cutting edge angle and the undeformed chip thickness are set by the cutting depth.
The knowledge of the process forces is thereby very important for the process design, e.g. for the dimensioning of the clamping. For this process, the occurring process forces are not possible to be calculated with simple cutting force models. Due to the complex and time-dependent undeformed chip geometry, a new approach to model the process forces is required and proposed in this paper.

\section{EXPERIMENTAL SETUP}

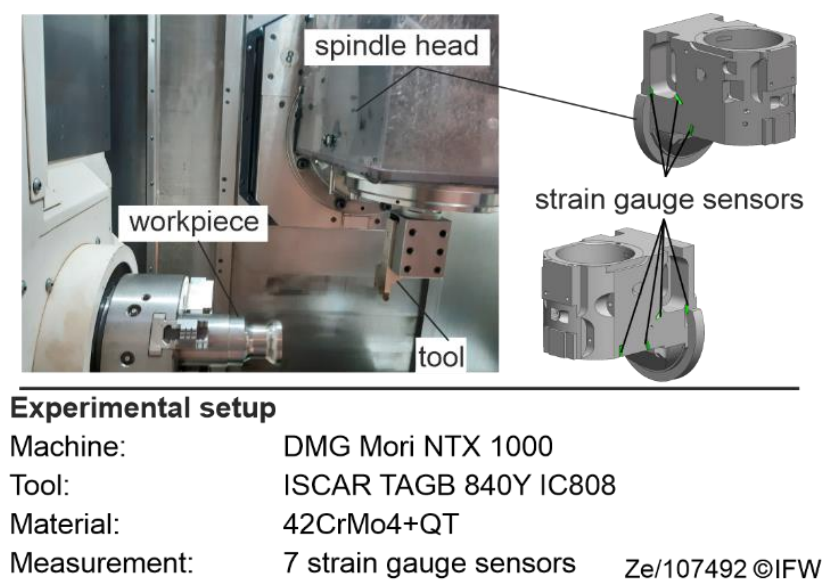

\section{Fig. 2 Experimental setup}

In order to investigate the process forces occurring during enhanced trochoidal turning processes, a reference process was conducted with varying cutting parameters. The experiments were carried out on a DMG MORI NTX 1000 turn-mill centre. The process forces were recorded using a spindle integrated strain gauge measuring system described in [Denkena 2018], which is shown in Fig. 2. In previous investigations, suitable positions for the strains of the spindle head were identified and the strain gauges were placed in notches at these positions. Since the strain gauges measure the force only by measuring the strain of the part, the achieved accuracy depends strongly on the stiffness of the used measurement points. Here, the measurement uncertainty of the force is between $30 \mathrm{~N}$ in Z-direction and $110 \mathrm{~N}$ in Y-direction, whereby the differences can be explained with higher stiffness of the spindle head in $Y$ direction [Denkena 2018]. Furthermore, the axis positions can be recorded during the process, which allows an exact simulation of the machine movements during the process.

TiAIN/AITiN+TiN-coated groove-turn inserts of the type ISCAR TAGB 840Y IC808 were used. The workpiece material was quenched/tempered $42 \mathrm{CrMo} 4$ with a tensile strength of $R_{m}=975 \mathrm{~N} / \mathrm{mm}^{2}$ and a diameter of $64 \mathrm{~mm}$. A large cutting edge rounding of $S_{\alpha}=114 \mu \mathrm{m}$ and $S_{Y}=72 \mu \mathrm{m}$ was chosen, which leads to an increased cutting edge strength necessary for the cutting conditions in this process [Denkena 2014]. 

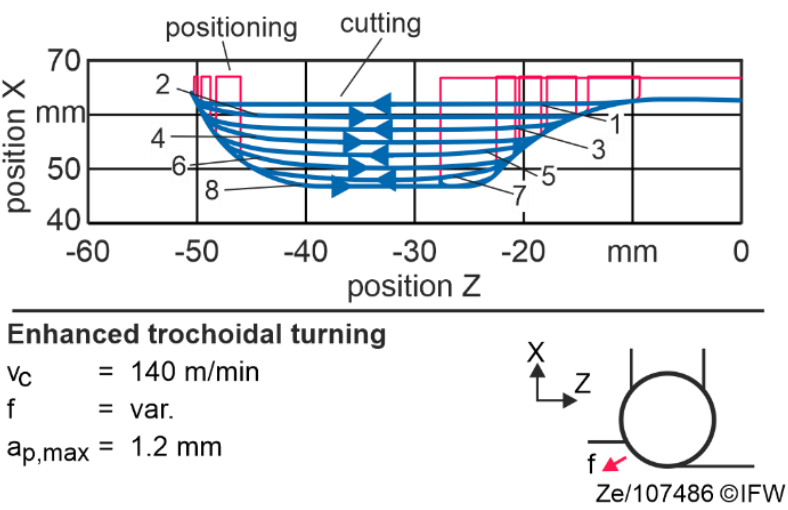

Fig. 3: Tool path of the enhanced trochoidial turning process

The tool path and the used cutting parameters are shown in Fig. 3. As described before, the tool path is optimized to achieve a constant maximum undeformed chip thickness. Due to this, the entry of the tool into the workpiece is performed in a smooth circular movement. To achieve an optimal maximum cutting edge angle, the movements during the cuts are performed as a combination of elongated circles.

\section{PROCESS FORCE MEASUREMENT}

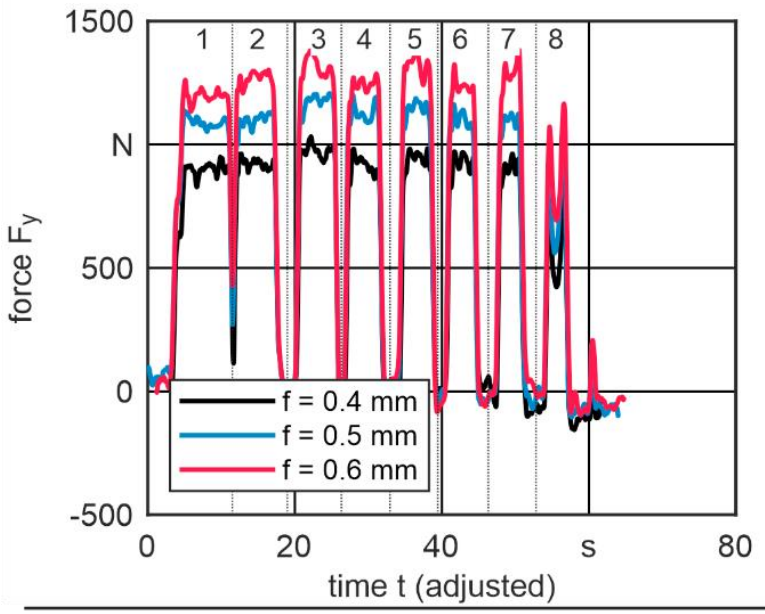

$$
\begin{aligned}
& \text { Process parameters } \\
& \mathrm{v}_{\mathrm{C}}=140 \mathrm{~m} / \mathrm{min} \text { Material: } 42 \mathrm{CrMo4+QT} \\
& \mathrm{f}=\text { var. } \\
& a_{p, \max }=1.2 \mathrm{~mm}
\end{aligned}
$$

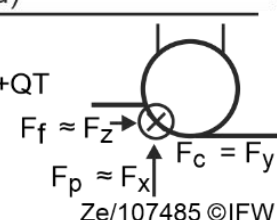

\section{Fig. 4: Forces measured in Y-direction}

In Fig. 4 the forces measured in Y-direction, which are the cutting forces, at various feed rates are shown. To allow an easy comparison of the forces at the different feed rates, the time is adjusted to the time of the process with a feed rate of $0.5 \mathrm{~mm}$. First of all, the data shows a low difference between the different cuts for each of the different feed rates, which can be explained with the concept of the advanced trochoidal turning process, which pursues a constant maximum undeformed chip thickness. As expected, the differences between the forces measured at different feed rates are less than proportional for the respective feed rate changes.

The forces measured in X-and Z-direction, shown in Fig. 5 and Fig. 6, can be seen as the components of the thrust force. Thus, they are a combination of the passive force and the feed force. Due to the tool path shown in Fig. 3, it can be noted that $F_{X}$ is equivalent to the passive force over most of the time, while $F_{Z}$ is equivalent to the feed force. It should be mentioned that the changes of the feed direction at the beginning and end of each cut can explain the change of the processes forces in these areas. It is also evident that these forces only change slightly for the different feed rates, which might indicate that they are for the selected range of feed rates independent from the undeformed chip thickness. As stated in [Denkena 2014], this can be attributed to the high cutting edge rounding.

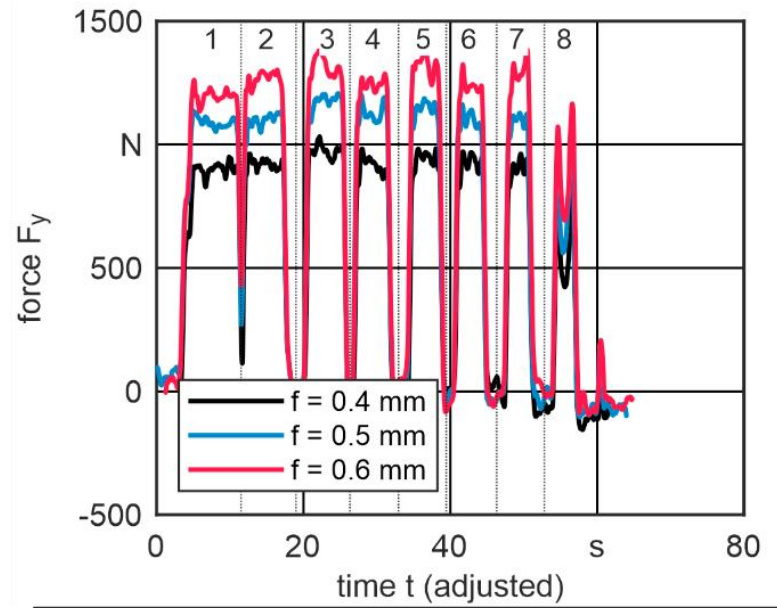

$$
\begin{aligned}
& \text { Process parameters } \\
& \mathrm{v}_{\mathrm{C}} \quad=140 \mathrm{~m} / \mathrm{min} \text { Material: } 42 \mathrm{CrMo4+QT} \\
& \mathrm{f}=\text { var. } \\
& a_{p, \max }=1.2 \mathrm{~mm}
\end{aligned}
$$

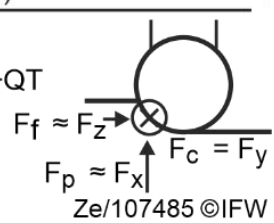

Fig. 5: Forces measured in $X$-direction

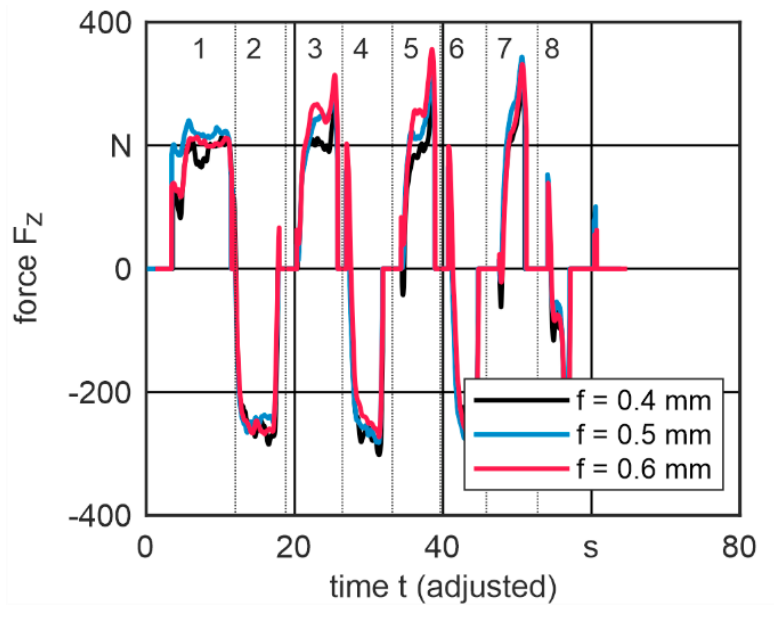

$$
\begin{aligned}
& \text { Process parameters } \\
& \mathrm{v}_{\mathrm{C}} \quad=140 \mathrm{~m} / \mathrm{min} \text { Material: } 42 \mathrm{CrMo}+\mathrm{QT} \\
& \mathrm{f} \quad=\text { var. } \\
& a_{p, \max }=1.2 \mathrm{~mm} \\
& \text { }
\end{aligned}
$$

\section{Fig. 6: Forces measured in Z-direction}

\section{SIMULATION APPROACH}

The approach proposed in this paper consists of two parts. First, a dexel-based model is used to estimate the shape of the undeformed chip for discrete time-steps. Thereafter, these geometries are used in a process force model, based on the process force model of Altintas [Altintas 2012], to calculate the process forces. 


\subsection{Material removal model}

The dexel-based material removal simulation is done in the software "IFW CutS" developed at the IFW. The software also includes the options to export the calculated dexel data and to control the toolpath from saved process data.

In conventional dexel models, the workpiece is approximated by equidistant grids of "bars", the length of which is determined by the surfaces of the workpiece. To achieve a greater accuracy, the grids in different coordinate directions are entangled [Ammermann 2017]. Since in turning processes, the workpieces are rotationally symmetrical and the relevant cutting parameters have to be calculated per revolution, a more efficient approach can be chosen by approximating the workpiece as a row of equidistant "discs", whose diameter is determined by the current surface of the workpiece. Similar to the conventional dexel model, the contact points between the dexel and the tool are identified and the diameter of the respective disc is changed accordingly. The cut dexels are used to estimate the shape of the undeformed chip. The workpiece is discretised with a resolution of $0.1 \mathrm{~mm}$, while the time is discretised based on a $2 \mathrm{~ms}$ time step. The material removal simulations were performed on an Intel i7 9700 processor, where it took 30 minutes each, including the export of the dexel data. The analysis was performed by MATLAB scripts.

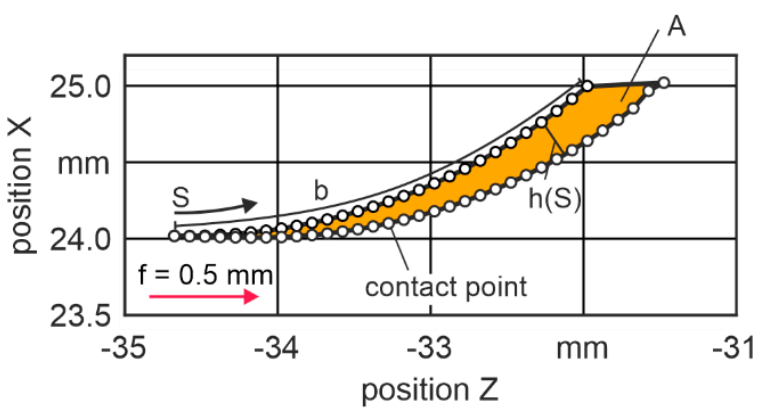

\begin{tabular}{lll}
\hline \multicolumn{2}{l}{ Simulation parameters } & \\
time & $t$ & $=46.5 \mathrm{~s}$ \\
time per turn & $t_{\text {turn }}$ & $=0.065 \mathrm{~s}$ \\
dexel resolution & $\Delta Z$ & $=0.1 \mathrm{~mm}$
\end{tabular}

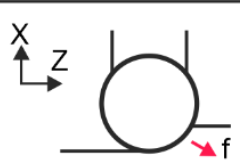

Ze/107487 @IFW

\section{Fig. 7: Simulated shape of the uncut chip}

In Fig. 7 the result for the shape of the uncut chip for one exemplary simulation step is shown. Based on the contact points between the dexels and the tool, parameters of the undeformed chip can be defined and calculated. These are especially the cross-section of the undeformed chip $A$, the width of the undeformed chip $b$ and the undeformed chip thickness $h$. The chip thickness is calculated based on the perpendicular to the cutting edge.

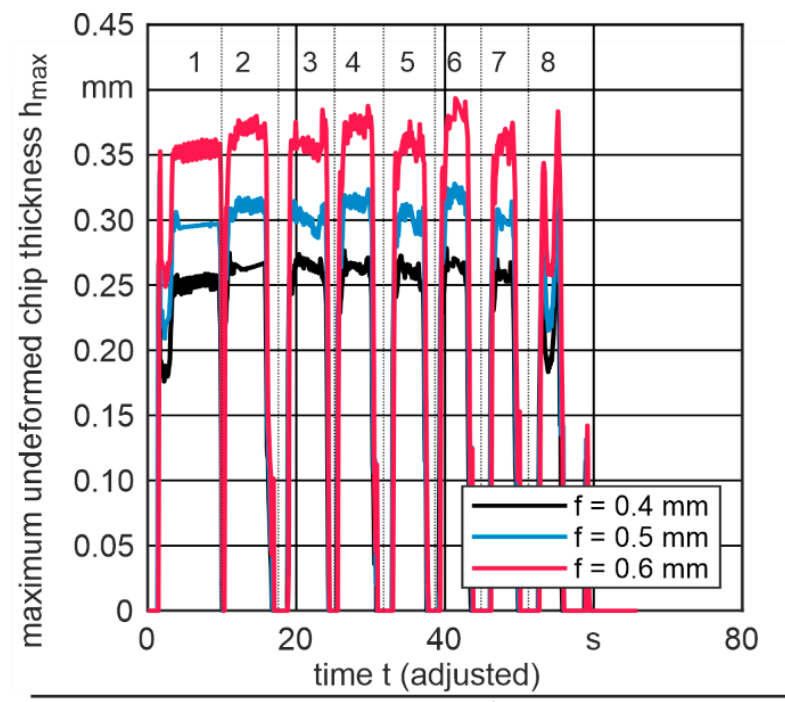

$$
\begin{aligned}
& \text { Process parameters } \\
& \mathrm{v}_{\mathrm{c}} \quad=140 \mathrm{~m} / \mathrm{min} \\
& \mathrm{f} \quad=\text { var. } \\
& a_{\mathrm{p}, \max }=1.2 \mathrm{~mm}
\end{aligned}
$$

\section{Fig. 8: Simulated maximum undeformed chip thickness}

Fig. 8 shows the maximum undeformed chip thickness over the time. To allow a better comparison between the different measurements, the time is adjusted to the time of the measurement at $f=0.5 \mathrm{~mm}$. As expected, the shape shows a general similarity with the measured process forces, especially the cutting forces. It also clearly illustrates the idea of the enhanced trochoidial turning concept, where the tool path is optimized, to achieve a constant maximum undeformed chip thickness. It should be noted, that the slight changes in the simulated undeformed chip thickness between the distinct points of times might be caused by inaccuracies due to the discretisation of the model and numerical uncertainties.

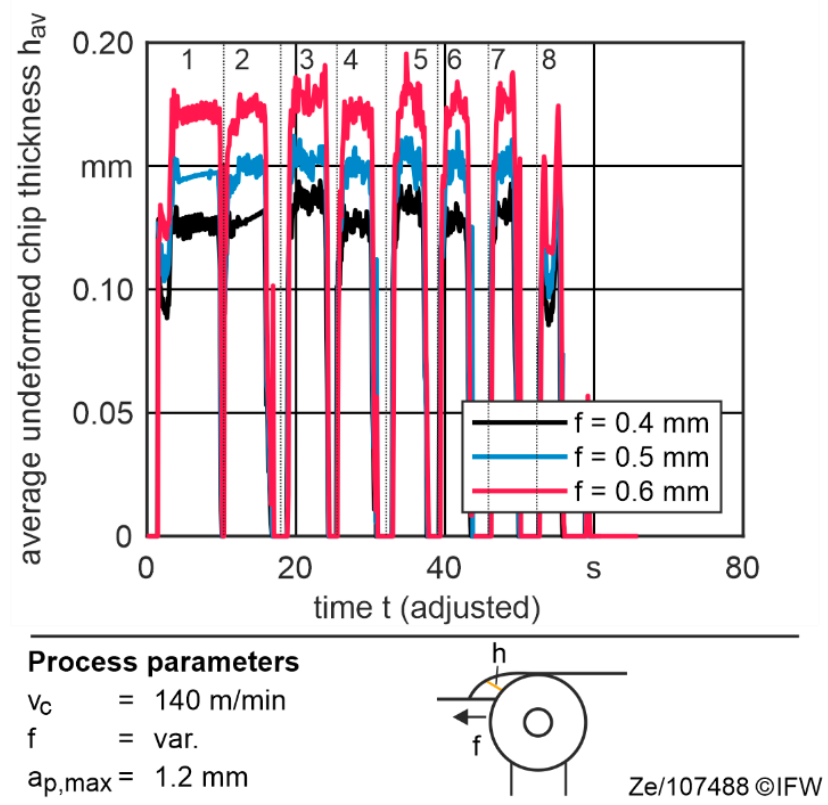

\section{Fig. 9: Average undeformed chip thickness}

The average undeformed chip thickness, which is shown in Fig. 9, is calculated as a weighted average based on the respective length of the cutting edge. Thus, the influence of the curved cutting edge can be taken into account, especially since the data for $h$ is only available at the discrete cutting points of the cutting edge, which are equidistant on 
the Z-axis. As expected, the average undeformed chip thickness follows the course of the maximum undeformed chip thickness shown before. As well, its course follows the measured cutting forces.

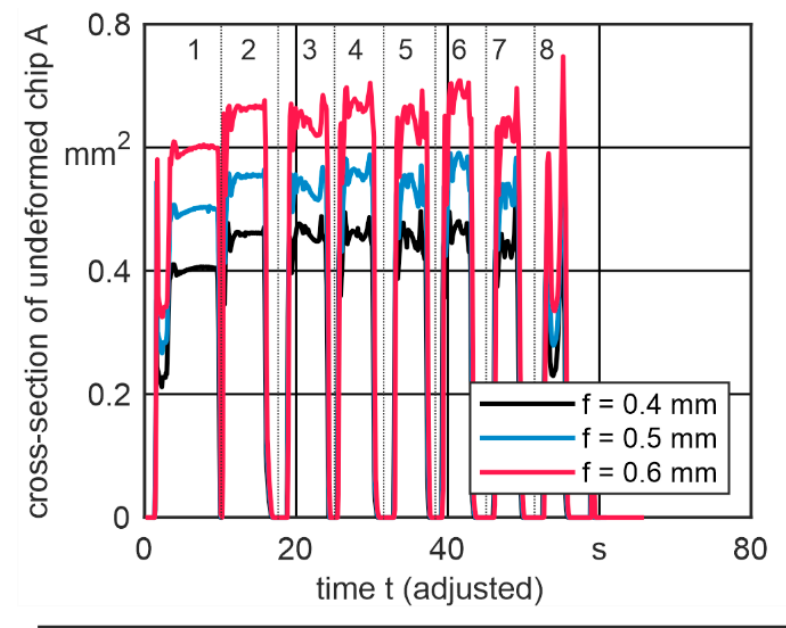

$$
\begin{aligned}
& \text { Process parameters } \\
& \begin{array}{ll}
\mathrm{v}_{\mathrm{C}} & =140 \mathrm{~m} / \mathrm{min} \\
\mathrm{f} & =\text { var. } \\
\mathrm{a}_{\mathrm{p}, \max } & =1.2 \mathrm{~mm}
\end{array}
\end{aligned}
$$

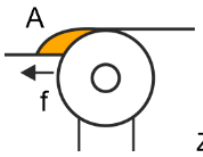

Ze/107488 ㅇIFW

\section{Fig. 10: Simulated cross-section of the undeformed chip}

Similar to the maximum and average undeformed chip thickness, the cross-section of the undeformed chip, which is shown in Fig. 10, displays only little variation between the different cuts and remains constant during each cut. Noticeable is the lower chip cross-section for the first cut, especially, when compared to the undeformed chip thickness, which is only slightly lower for the first cut. This might be explained by the optimization of the maximum undeformed chip thickness, whereby the cross-section of the undeformed chip is not considered.
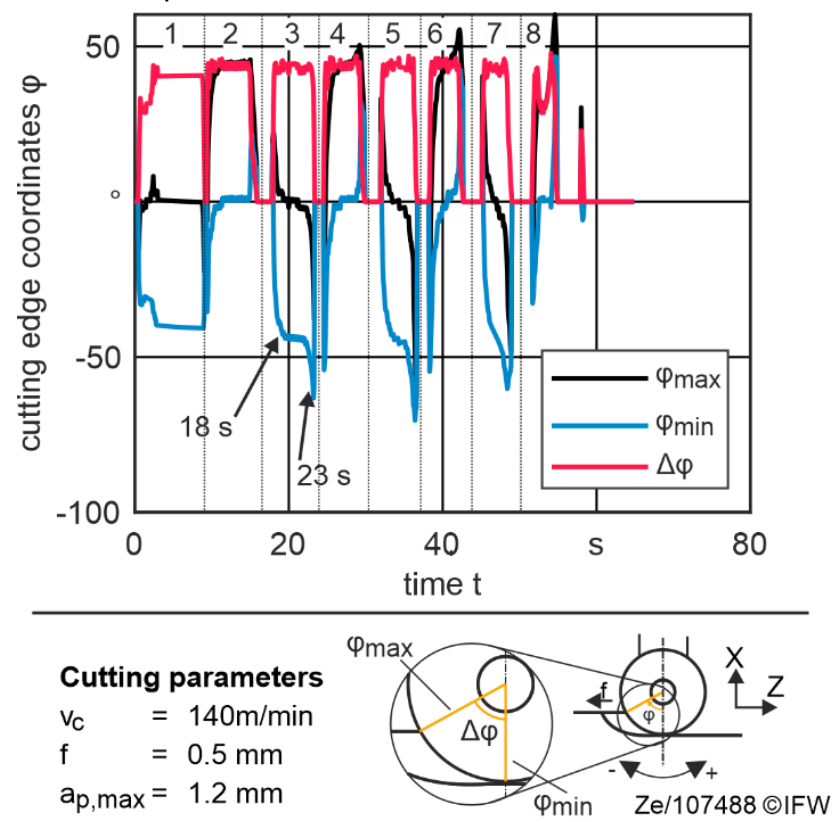

Fig. 11: Simulated minimum and maximum engaged cutting edge in $\varphi$

As described before, the investigated process is based on an optimization towards a constant maximum cutting edge angle which depends on the cutting depth. Therefore, a nearly constant width of the undeformed chip is to be expected. Furthermore, nearly the same length of the cutting edge should be engaged. Since the process consists of cuts in various directions, the engaged area of the cutting edge should change permanently, while the length of the cutting edge engaged should remain virtually constant. For a round cutting insert, the engaged cutting edge can as well be described by the wrap angle. In Fig. 11 the wrap angle $\Delta \varphi$ as well as the position of the engaged cutting edge, described by the angular coordinates $\varphi_{\min }$ and $\varphi_{\max }$, is displayed. As expected, the wrap angle remains largely constant during the process. Regarding the position of the engaged cutting edge, first of all the different directions of the different cuts and the usage of the cutting edge on both sides of the tool can be clearly seen. Furthermore, the entrance and exit movements of the tool can also be clearly seen in the changes of $\varphi_{\min }$ and $\varphi_{\max }$ at the beginning and end of each cut. With this, also the shifts between the forces in $\mathrm{X}$ and in Z-direction seen in the measurements can be explained. While in Fig. 3 the toolpath composition of smooth circular movements is nearly not recognisable, it can be clearly seen due to the constant changes of the position of the engaged cutting edge.

In Fig. 12 the uncut chip forms for the time $19 \mathrm{~s}$ (tool entry) and $23 \mathrm{~s}$ (tool exit) of the reference process with a feed rate of $0.5 \mathrm{~mm}$ are shown. Here, the mentioned effect of the movement of the engaged part of the cutting edge during the process can be clearly seen. As expected, the uncut chip form for the different points of time is nearly the same, despite a rotation according to the respective direction of the feed.
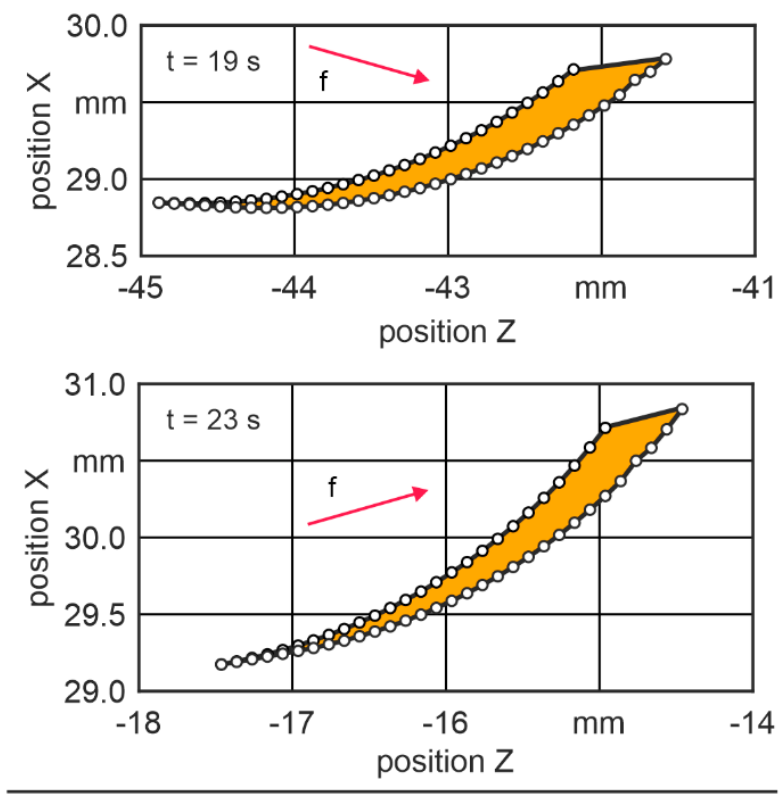

$$
\begin{aligned}
& \text { Process parameters } \\
& \begin{array}{ll}
\mathrm{v}_{\mathrm{C}} & =140 \mathrm{~m} / \mathrm{min} \\
\mathrm{f} & =0.5 \mathrm{~mm} \\
\mathrm{a}_{\mathrm{p}, \max } & =1.2 \mathrm{~mm}
\end{array}
\end{aligned}
$$

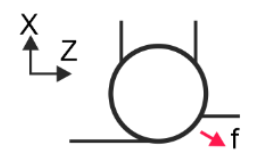

Ze/107487 @IFW

Fig. 12: Comparison of uncut chip shapes 


\subsection{Process force model}

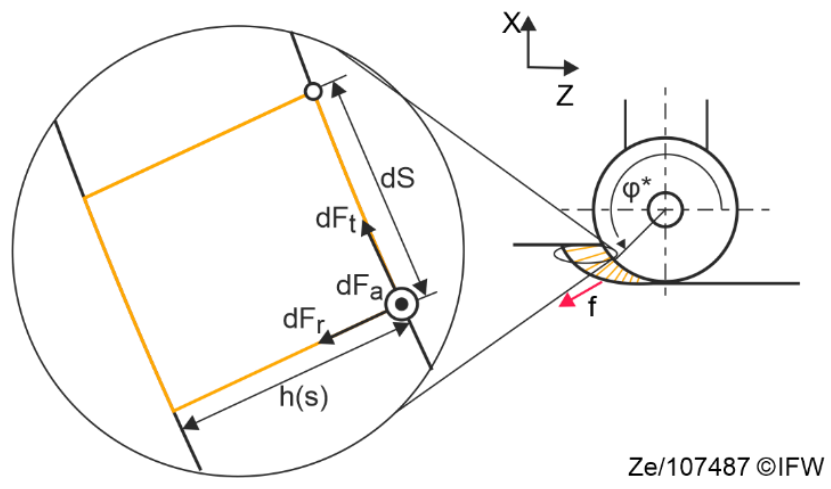

Fig. 13: Direction of force components

The used process force model is based on an approach introduced in [Denkena 2019] and adapted to turning processes:

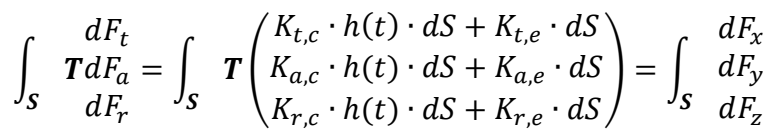

In this approach, the active cutting edge $S$ is divided in incremental elements $d S$. For each of these incremental elements, a local coordinate system is defined, as seen in Fig. 13. With these local coordinate systems, the different orientations of the cutting edge elements and thus the process forces are taken into account. To transform these forces, given in the respective local coordinate system, into the machine coordinate system, the transformation matrix $\boldsymbol{T}$ is used:

$\boldsymbol{T}=\left(\begin{array}{ccc}\sin \left(\varphi^{*}\right) & 0 & \cos \left(\varphi^{*}\right) \\ 0 & 1 & 0 \\ -\cos \left(\varphi^{*}\right) & 0 & \sin \left(\varphi^{*}\right)\end{array}\right)$

It should be noted that here the angle of the cutting edge is described as $\varphi^{*}$, which is zero in the positive Z-axis, while the previous used $\varphi$ is zero in the negative $X$-axis.

The process force in the respective direction is derived from the force coefficients $K_{c}$ and $K_{e}$. While $K_{c}$ represents the shearing forces during cutting, which are influenced by both, the chip thickness and the length of the engaged cutting edge, $K_{e}$ represents the edge forces, which are influenced by the length of the engaged cutting edge. [Altintas 2012]

To parametrize the model, a mechanistic approach instead of an oblique cutting model is chosen. This choice is due to the advantages of the mechanistic model mentioned above, especially the greater accuracy of the mechanistic model compared to the oblique cutting model.

Since the force coefficients in this linear force model are independent from the cutting conditions, they can be excluded from the integral:

$\int_{S} \begin{aligned} & d F_{x} \\ & d F_{y} \\ & d F_{z}\end{aligned}=\left(\int_{S} \boldsymbol{T} \cdot h(t) d S\right)\left(\begin{array}{l}K_{t, c} \\ K_{a, c} \\ K_{r, c}\end{array}\right)+\left(\int_{S} \boldsymbol{T} \cdot d S\right)\left(\begin{array}{l}K_{t, e} \\ K_{a, e} \\ K_{r, e}\end{array}\right)$

By using a numerical summation instead of an integration over the cutting edge, this can be written as the variable of the cutting parameters $c_{i}$ in the workpiece coordinate system. The parameter $c_{1}$ is thereby the result of the transformation matrix, the undeformed chip thickness $h$ and the incremental cutting edge length dS. This can be written for each time step as: $\sum_{i=t, r, a} c_{i, c}(t) \cdot K_{i, c}+\sum_{i=t, r, a} c_{i, e}(t) \cdot K_{i, e}=\boldsymbol{F}_{\text {sim }}(t)=\boldsymbol{F}_{\text {exp }}$

Here $\boldsymbol{F}_{\text {exp }}$ are the measured process forces, which are used to calibrate the process force model.

Based on this we have a linear system of equations with the six force coefficients $K_{\mathrm{i}}$ as unknown variables. Since the process force has three different components, two measured process forces with different feed rate are needed. Theoretically, the evaluation of a single rotation of the workpiece would be sufficient. Because this would ignore statistical uncertainties, like inhomogeneities in the material properties, small stochastic deflections of the tool or the stochastic error of the measurement, the measurements are evaluated for multiple points of time.

The equation system was solved using the feed rates of $0.4 \mathrm{~mm}$ and $0.5 \mathrm{~mm}$. Since the forces $F x$ and $F z$ are hardly changing for the different investigated feed rates, it is implied that the forces corresponding with $\mathrm{h}$ are primarily acting in the direction of $F_{a}$. Especially the friction forces on the rake face, caused by an increasing $h$, are low. Due to this the factors $K_{t, c}$ and $K_{a, c}$ can be neglected. The resulting force coefficients are shown in Table 1.

Table 1: Force coefficients

\begin{tabular}{|l|l|l|}
\hline $\mathrm{K}_{\mathrm{t}, \mathrm{c}}$ & $\mathrm{K}_{\mathrm{a}, \mathrm{c}}$ & $\mathrm{K}_{\mathrm{r}, \mathrm{c}}$ \\
\hline $0 \mathrm{~N} / \mathrm{mm}^{2}$ & $2613 \mathrm{~N} / \mathrm{mm}^{2}$ & $0 \mathrm{~N} / \mathrm{mm}^{2}$ \\
\hline $\mathrm{K}_{\mathrm{t}, \mathrm{e}}$ & $\mathrm{K}_{\mathrm{a}, \mathrm{e}}$ & $\mathrm{K}_{\mathrm{r}, \mathrm{e}}$ \\
\hline$-91.84 \mathrm{~N} / \mathrm{mm}$ & $58.04 \mathrm{~N} / \mathrm{mm}$ & $15.27 \mathrm{~N} / \mathrm{mm}$ \\
\hline
\end{tabular}

\subsection{Validation}

To validate the derived model, the process forces of the reference process are calculated for a feed rate of $0.6 \mathrm{~mm}$ and compared with the measurement. As shown in Fig. 14, a quite accurate modelling of the process forces is possible. Especially the changes in the direction of the forces in Xund Z-direction, when entering into the workpiece or when exiting from the workpiece, can clearly be seen.

Of interest is, that the modelled forces in $Y$-direction show a much closer match then the forces for $X$ and $Z$. For this, the measurement method based on strain gauges has to be taken into account, which always includes a certain level of measurement noise independently from the load. Since only the strain part is measured, of course the absolute value of noise due to the strain gauges depends on the stiffness of the spindle head. Even though, as mentioned above, the stiffness of the spindle head in X-and Z-direction is much lower than the stiffness in $Y$-direction, the measured forces in $X$ and $Z$-direction are also much lower. Therefore, the ratio between noise and desired force is much better for $Y$ than it is for $X$ and $Z$. This effect is increased by the fact that the force coefficients are also based on measurements with strain gauges. Thus, they are also disturbed by the stochastic error of the strain gauges.

In general, the proposed model reflects the characteristics of the investigated process, e.g. behaviour during the tool entry and exit. Hereby, different uncut chip shapes occur, which are modelled by the simulation and applied to calculate the forces. With this, the process characteristics (e.g. feed rate) can be optimized with respect to available spindle power, tool limits or maximum clamping forces. 

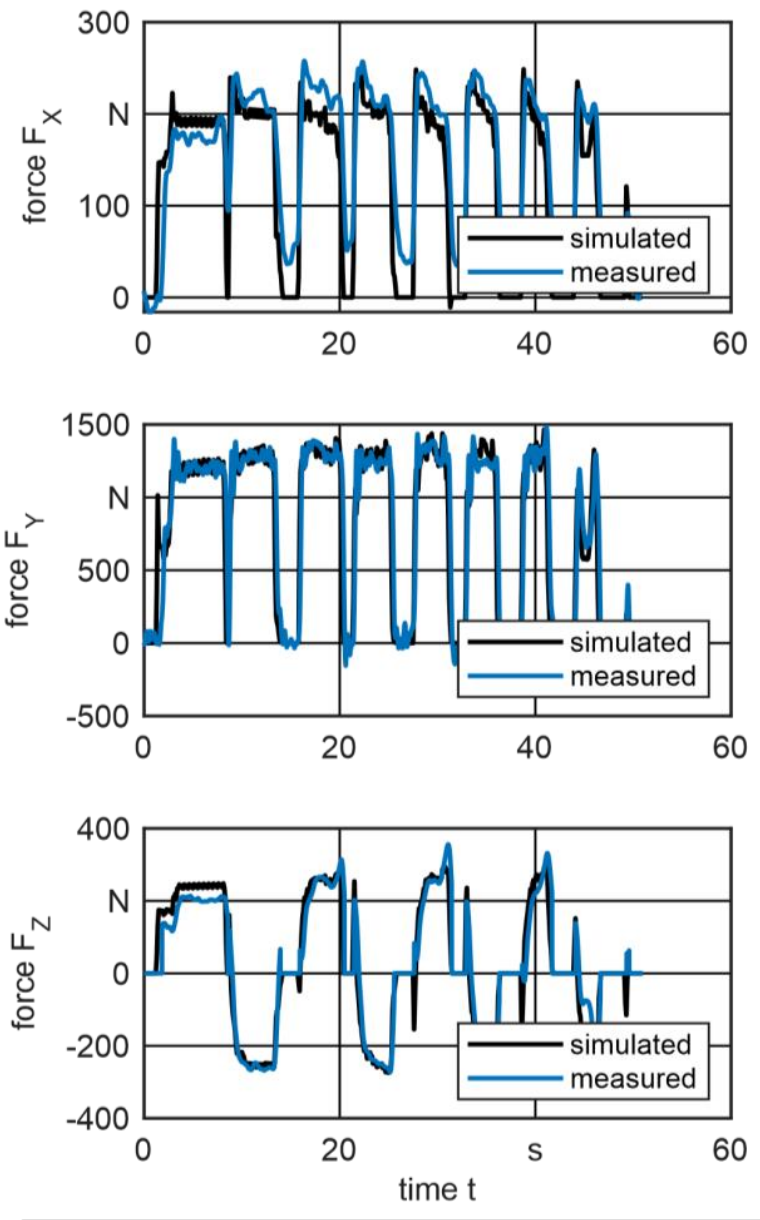

$$
\begin{aligned}
& \text { Process parameters } \\
& \mathrm{v}_{\mathrm{C}}=140 \mathrm{~m} / \mathrm{min} \text { Material: } 42 \mathrm{CrMo4}+\mathrm{QT} \\
& \mathrm{f} \quad=0.6 \mathrm{~mm}
\end{aligned}
$$

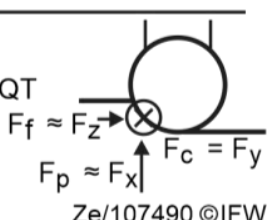

Fig. 14: Comparision of simulated and measured process forces

\section{SUMMARY}

This article presents an approach for the modelling of process forces of enhanced trochoidal turning processes. First, a reference process with the feed rate varied in three steps was conducted to gain insights on the process forces. Based on a material removal simulation, which is specially adapted for turning processes, a process force model based on the model introduced by Altintas is proposed. The model parameters of the process force model are calibrated with measurement data of the reference process. Furthermore, the model is validated by calculating the process forces for the reference process with a different feed rate. Measured and simulated process forces are in good agreement. In further works, the model has to be expanded for different process parameters, like higher feed rates and other cutting speeds. Furthermore, other complex multiaxial turning processes and combinations of tools and materials should be investigated and implemented in the model.

\section{ACKNOWLEGEMENT}

The IGF-project (IGF $-21131 \mathrm{~N}$ ) of the Research Association (VDW - Forschungsinstitut e.V.) was supported by the AiF within the program for the promotion of industrial research (IGF) from the Federal Ministry of Economy and Energy due to a decision of the German Bundestag. The authors would like to thank Iscar Germany $\mathrm{GmbH}$ for providing the cutting tools.

\section{REFERENCES}

[Altintas 2012] Altintas, Y. Manufacturing Automation. Cambridge: Cambridge University Press, 2012. ISBN 9781107001480

[Ammermann 2017] Ammermann, C. Einsatzsimulation für die Werkzeugentwicklung. Dissertation. Garbsen: TEWISS Verlag, 2021. ISBN 3959001401

[Arrazola 2013] Arrazola, P., et al. Recent advances in modelling of metal machining processes. CIRP Annals, 2013, Vol. 62, No. 2, p. 695-718

[Denkena 2014] Denkena, B. and Biermann, D. Cutting edge geometries. CIRP Annals, 2014, Vol. 63 No. 2, p. 631-653

[Denkena 2018] Denkena, B. and Boujnah, H. Feeling machines for online detection and compensation of tool deflection in milling. CIRP Annals, 2018, Vol. 67, No. 1, p. 423426

[Denkena 2019] Denkena, B., et al. Optimization of complex cutting tools using a multi-dexel based material removal simulation. Procedia CIRP, 2019, Sheffield, 13-14 June, 2019, p. 379-382, ISSN 2212-8271

[Dorlin 2016] Dorlin, T., et al. Generalised cutting force model including contact radius effect for turning operations on Ti6Al4V titanium alloy. The International Journal of Advanced Manufacturing Technology, 2016, Vol. 86, No. 9-12, p.oe297-3313

[Koehler 2010] Koehler, J. Berechnung der Zerspankräfte bei variierenden Spanungsquerschnittsformen. Dissertation. Garbsen: TEWISS Verlag, 2010. ISBN 9783941416512

[Lorong 2011] Lorong, P., et al. Dynamic Study of Thin Wall Part Turning. AMR (Advanced Materials Research), 2011, Vol. 223, p. 591-599

[Victor 1952] Victor, H. and Kienzle, O. Die Bestimmung von Kraeften und Leistungen an spanenden Werkzeugmaschinen. VDI-Z, Vol. 94, p. 299-305

[Weng 2017] Weng, J., et al. An analytical force prediction model for turning operation by round insert considering edge effect. International Journal of Mechanical Sciences, 2017, Vol. 128-129, p. 168-180

[Zaeh 2009] Zaeh, M. F. and Schwarz, F. Implementation of a process and structure model for turning operations. Engineering Production, 2009, Vol. 3, No. 2, p. 168-180 